\title{
Enhanced ETCS_L3 train control system
}

\author{
D. Emery \\ EPFL: École polytechnique fédérale de Lausanne, Switzerland \\ LITEP: Laboratory for Intermodality and Transport Planning, \\ Switzerland
}

\begin{abstract}
The last decade has seen the development of the European Train Control System ERTMS/ETCS. This Automatic Train Protection system (ATP) was designed in three versions: ETCS Level 1, 2 and 3. ETCS_Level 3 uses moving blocks and provides short headways. However, ETCS_Level 2 may also offer short headways provided suitable block sections' length.

The proposed train control system is an enhancement of ETCS-Level 3. It could also be considered as an enhancement of ETCS Level 2. Its main advantage compared to other ATP systems is to provide even shorter headways, offering potential for capacity increases, especially for busy High Speed Lines (HSL).
\end{abstract}

Keywords: braking curves, capacity, ETCS, ERTMS, high speed line, interlocking, moving block.

\section{Interoperability, safety and capacity with ETCS}

\subsection{ETCS for interoperability and safety}

The European Train Control System was firstly developed to offer to the European Rail community a common Automatic Train Protection system in replacement of the existing ones. In theory, this is needed urgently as more than 15 different and incompatible ATP systems equip the European main rail networks (cf. table 1) [1], which obviously preclude interoperability.

The Eurobalise is a local transponder providing trains with a lot of information on the downstream route attributes and speed limits. It could replace any kind of balises or contacts used today by ATP-systems on conventional lines. It makes it possible to implement a continuous speed control, in particular 
between the distant signal and its corresponding main signal. ETCS is thus able to offer higher security than many of the ATP systems currently in service through Europe.

On high-speed lines, the cab-signalling is compulsory, and ATP-systems are logically coupled with cab-signalling. The cab-signalling that is part of ETCS is named Eurocab. Euroradio, a radio system using at this time a GSM-R layer, makes the transmission of signalling information from ground to Eurocab on high speed lines. The main advantage of using a radio system is the ability to transmit a high amount of data in both directions without installing equipments in the tracks (cf. table 2).

Table 1: $\quad$ ETCS and some ATP spot transmission.

\begin{tabular}{|l|c|c|c|c|}
\hline & $\begin{array}{c}\text { Crocodile } \\
\text { (France, Belgium) }\end{array}$ & $\begin{array}{c}\text { KVB } \\
\text { (France) }\end{array}$ & $\begin{array}{c}\text { Indusi, PZB } \\
\text { (Germany) }\end{array}$ & $\begin{array}{c}\text { ETCS L1 } \\
\text { and higher }\end{array}$ \\
\hline $\begin{array}{l}\text { Transmission } \\
\text { system }\end{array}$ & $\begin{array}{c}\text { Electric through } \\
\text { mechanical contact }\end{array}$ & Transponder & Magnetic & Transponder \\
\hline
\end{tabular}

Table 2: $\quad$ ETCS and high speed line signalling systems [2].

\begin{tabular}{|l|c|c|c|c|}
\hline & $\begin{array}{c}\text { TVM 430 } \\
\text { (France) }\end{array}$ & $\begin{array}{c}\text { BACC } \\
\text { (Italy) }\end{array}$ & $\begin{array}{c}\text { LZB } \\
\text { (Germany) }\end{array}$ & $\begin{array}{c}\text { ETCS L2 and } \\
\text { higher }\end{array}$ \\
\hline Data transmission & coded track circuit & trackside cable & radio transmission \\
\hline Data flow limitations & \multicolumn{2}{|c|}{ mono-directional } & \multicolumn{2}{|c|}{ bi-directional } \\
\hline
\end{tabular}

\subsection{ETCS and line capacity}

The limitation of railway line capacity on conventional lines without cabsignalling is mainly due to the fact that the stop distance of a train must be shorter than the cumulative length of only a very few block sections.

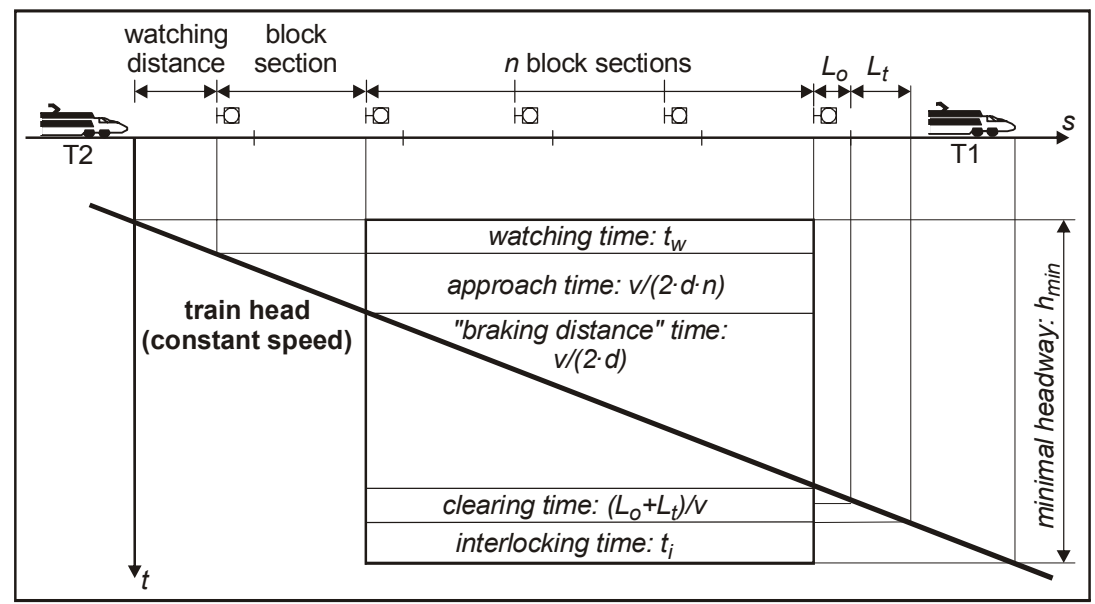

Figure 1: $\quad$ Minimal headway. 
If we consider a route at level gradient and a constant deceleration, the minimum headway between two similar trains succeeding at the same speed $v$ is

$$
h_{\min }=t_{w}+\frac{(1+1 / n) \cdot v}{2 \cdot d}+\frac{L_{o}+L_{t}}{v}+t_{i}[\mathrm{sec}]
$$

With: $t_{W}=$ watching time [sec], $n=$ number of block sections needed by a train to stop from ceiling speed, $d=$ safe mean deceleration $\left[\mathrm{m} / \mathrm{s}^{2}\right], v=$ speed $[\mathrm{m} / \mathrm{s}]$, $L_{O}=$ overlap length $[\mathrm{m}], L_{t}=$ train length $[\mathrm{m}]$ and $t_{i}=$ interlocking time [sec]

With cab-signalling, the number of block sections $n$ can be raised substantially. For trains running at $300 \mathrm{~km} / \mathrm{h}$, and if we consider standard values for trains and infrastructure, splitting the stopping distance into 6 instead of 5 blocks reduces the headway by only 3 seconds!

As headways may already be significantly shortened, with the sole use of cabsignalling and short track sections, solutions like CIR-ELKE [3], LZB or ETCS_L2 [4] offer already a high capacity level.

Pushing $n$ asymptotically towards infinity and using standard values for some fixed variables, eqn (1) tends to its simpler form (2):

$$
h_{\min }=\frac{v}{2 \cdot d}+\frac{500}{v}+10[\mathrm{sec}]
$$

With: $d=$ safe mean deceleration $\left[\mathrm{m} / \mathrm{s}^{2}\right], \quad v=$ speed $[\mathrm{m} / \mathrm{s}], \quad L_{O}=100 \mathrm{~m}, \quad L_{t}=$ train length $=400 \mathrm{~m}$, and $t_{w}+t_{i}=$ watching, interlocking and system time $=10 \mathrm{sec}$

Actually, additional capacity gains by the use of moving block, as proposed by ETCS_L3, are relatively small compared to ETCS_L2 [4]: the maximum saving is about 10 seconds ( $\mathrm{n}>>6$ versus $\mathrm{n}=6$ ) at $300 \mathrm{~km} / \overline{\mathrm{h}}$.

At high speed, minimum headway is mainly determined by its component related to the braking distance (the initial part of eqn (2): v/2.d). Thus, the only way to further reduce it significantly is to accept operation based also on relative braking distances, and that is the purpose of the following sections to present a possible implementation of this concept.

\section{REBAD: To get over the absolute service braking distance}

\subsection{Absolute and relative braking distance}

Classic block systems or today moving block systems use absolute service brake distances to separate the trains (cf. fig.2-A-Case). Such systems ensure that in front of each running train there is a cleared distance at least equal to a full stopping distance.

On the other hand, a system of train separation based on relative braking distances considers that a part of the braking distance, needed by the following train, could be occupied by the preceding one. This part is supposed to be released early enough, before the arrival of the second train (cf. fig.2-B-Case).

The main problem with relative braking distances is the risk that the second train collides with the rear-end of the first train that has been brought to a sudden halt (accident) or decelerated with an unexpectedly rate. It should be noticed that 
some risks to experience secondary accidents on double track lines are nowadays already accepted; this may be the case of a derailing train that fouls the gauge of the opposite track. This is not a reason however to accept extra secondary accident risks, particularly if a first accident would immediately be followed by several consecutive accidents involving trains following each other on the same track.

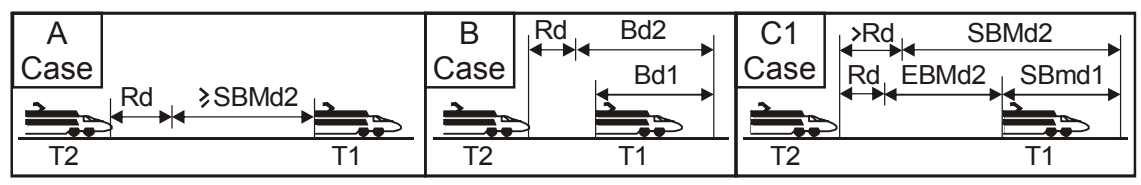

Figure 2: Running in absolute or relative braking distances A Case: in service brake absolute distance B Case: in service brake relative distance $\mathrm{C} 1$ Case: in emergency brake absolute distance. With: Rd: regulation distance, 1: train T1, 2: train T2, SBMd: Service Brake Maximal distance, SBmd: Service Brake minimal distance, Bd: Braking distance, and EBMd: Emergency Brake Maximal distance.

The regulation distance $\mathrm{Rd}$ is a buffer distance depending on the rate of transmission of information from train T1 to train T2, of the speed, and of the level of the traction-brake control system of train $\mathrm{T} 2$.

\subsection{Running and braking with REBAD}

The novelty of REBAD ("Running with Emergency Brake Absolute Distance") is to combine absolute braking distance with relative braking distance in order to reduce the train separation time between trains following each other. Parameters adopted by REBAD must be chosen in a way that no secondary accidents could occur.

REBAD is not a new level of ETCS but could become a new mode of ETCS_L2 or L3. As described below, running in REBAD mode is not easy (speed docking, speed regulation, short reaction time, etc.). Then, this mode should be considered as an ATO mode.

When two trains run at almost the same speed, two secure modes of running at minimal headway are possible (cf. fig. 3)

The adhesion conditions must be taken into great consideration, in particular to determine the minimal deceleration guaranteed by the emergency braking system. For evaluations made here the Emergency Brake minimal Deceleration $\mathrm{EBmD}$ is considered to be slightly lower than the Service Brake Maximal Deceleration SBMD (cf. fig 4).

The condition to be in the C1-Case is:

$$
\frac{P 2 \cdot v^{2}}{2 \cdot L_{0} \cdot P 2+v^{2}}-\frac{E B m D 2 \cdot S B M D 1}{E B m D 2+S B M D 1}>0
$$

In practice, this inequality could be true or not, so we have to continue to consider both the $\mathrm{C} 1$ and $\mathrm{C} 2$ Cases. 


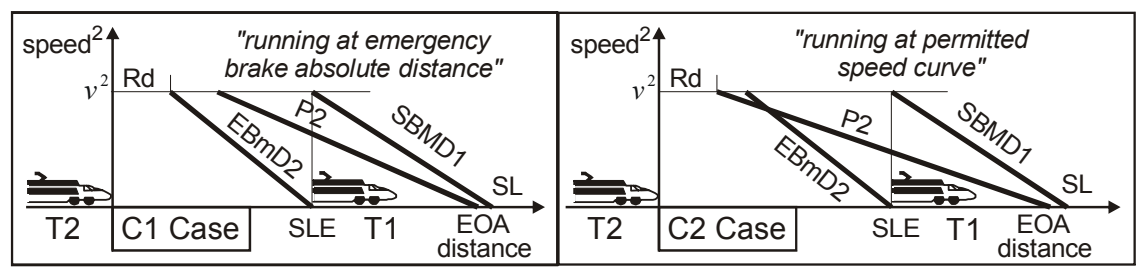

Figure 3: Two cases of very short successions of trains in REBAD (EOA: End Of Authority, SL: Supervised Location, SL$\mathrm{EOA}=\mathrm{L}_{0}=$ Overlap, SLE: Supervised Location in case of Emergency). With: Rd: regulation distance, 1: train T1, 2: train T2, EBmD: Emergency Brake minimal Deceleration, P: Permitted Speed Deceleration, SBMD: Service Brake Maximal Deceleration.

The C2-Case providing longer headways than the C1-Case, C2-case is kept for comparison of headways between ETCS_L3 and REBAD. At $300 \mathrm{~km} / \mathrm{h}$ minimal headway with REBAD could be shorter of more than $40 \mathrm{sec}$.

In normal operation, the worst case to deal with is when train $\mathrm{T} 1$ has a Service Brake Maximum Deceleration SBMD1 better than the following train T2. One must be sure than the Service Brake minimum Deceleration SBmD2 of train T2 is high enough to always maintain the absolute emergency braking distance between the rear-end of $\mathrm{T} 1$ and the front-end of $\mathrm{T} 2$.

So we consider $\mathrm{v}_{1}$ as the original speed, $\mathrm{v}_{2}$ as the goal speed, $\mathrm{v}_{2}<\mathrm{v}_{1}$, $\mathrm{SBmD} 2<\mathrm{SBMD} 1$, the absolute emergency braking distance is respected, in the C1 Case, if

$$
\frac{v_{1}^{2}-v_{2}^{2}}{2 \cdot E B m D 2} \geq \frac{v_{1}^{2}-v_{2}^{2}}{2 \cdot S B m D 2}-\frac{v_{1}^{2}-v_{2}^{2}}{2 \cdot S B M D 1}-v_{2} \cdot\left[\frac{v_{1}-v_{2}}{S B m D 2}-\frac{v_{1}-v_{2}}{S B M D 1}\right]
$$

With: Rd: regulation distance, 1: train T1, 2: train T2, SBMD: Service Brake Maximal Deceleration, SBmD: Service Brake minimal Deceleration, and EBmD: Emergency Brake minimal Deceleration

This inequality is true for instance with $\mathrm{v}_{2}=0$ if $\mathrm{SBmD} 2$ is at least the half of $\mathrm{EBmD} 2$ and the half of SBMD1.

In the $\mathrm{C} 2$ Case, the inequality is given by:

$$
v_{2} \cdot\left(v_{1}-v_{2}\right) \cdot \frac{S B M D 1-P 2}{S B M D 1 \cdot P 2} \geq 0
$$

This inequality is true if SBMD1 is greater than $\mathrm{P} 2$.

At this point we have to precise that decelerations are not constant but vary a lot according to types of brake devices, coordination of brake systems, speed, gradients, and action of wheel-slide devices. So decelerations have to be calculated according to a braking model (cf. fig. 4) [5-7].

With the electro-pneumatic brake system EP for high speed train sets, the equivalent time of brake application is about 3 seconds. 
The stopping distance from $300 \mathrm{~km} / \mathrm{h}$ to $0 \mathrm{~km} / \mathrm{h}$ following the B-curve is 4'690m, and the minimal mean deceleration for an emergency braking is $0.74 \mathrm{~m} / \mathrm{s}^{2}$. This value is impacted by gradient.

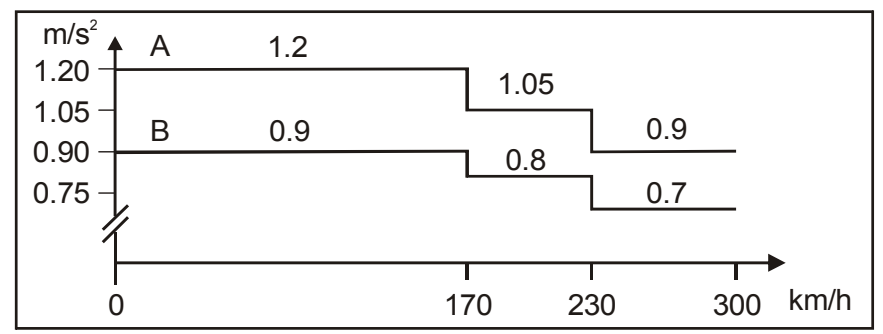

Figure 4: Emergency Brake minimal Decelerations EBmD [5] A: with certain equipment isolated B: like A plus unfavourable climatic conditions.

\subsection{Regulation distance and emergency braking in REBAD}

The regulation distance $R_{d}$ is crucial to engage in time the braking of train $T 2$ if needed. A quasi-permanent transmission of information has to be transmitted from train T1 to train T2 directly or through the RBC (cf. fig. 5). In a train sequence, the train that follows should permanently adapt its speed to the one that leads, in order to ensure that it is able to stop before reaching the rear of the preceding train. The status of the preceding train is also needed by the following one in order to start an emergency brake if necessary.

\subsection{From ETCS_L3 to REBAD and reverse}

The change from REBAD to ETCS_L3 (or ETCS_L2) is quite easy; the only thing to do is to fix the SL of the following train, till the previous train passes this point.

At contrary, the change from ETCS_L3 (or ETCS_L2) to REBAD needs speed docking procedures.

\section{ETCS_L2, ETCS_L3 and REBAD}

\subsection{ETCS curve family, SBMD and EBmD}

According to the most restrictive static speed profile of the track and of the train, and considering the braking performances of the train, the ETCS onboard computer calculates at least 6 braking curves (P, W, SBI, SBD, EBI, EBD) and perhaps also the indication curve I, or the guidance curve GUI that may replace the $P$ curve [8].

REBAD uses the same group of curves in order to supervise a usual stop at an EOA (End Of Authority) or the required speed at a LOA (Limit of Authority). 
However REBAD demands the computation of two new curves. The first one, using the service brake maximum deceleration SBMD, is needed for determining the minimum distance a train could run with full application of service brakes. This value will be used to determine the EOA of the following train.

The second one, using an emergency brake minimum deceleration $\mathrm{EBmD}$, is needed for determining the maximum distance the train runs with application of emergency brakes. This value will be used to determine how near a train could follow another train.

\subsection{Main data exchanges with ETCS_L2, ETCS_L3 and REBAD}

For migrating from ETCS_L2 to ETCS_L3, two challenges have to be dealt with:

- accurate acquisition and reliable transmission of the positions of the trains;

- certainty of train integrity and reliable transmission of the information.

For achieve REBAD, we need:

to gather not only the location but also the accurate speed of trains and to transmit them reliably;

- $\quad$ to additionally transmit train status parameters.

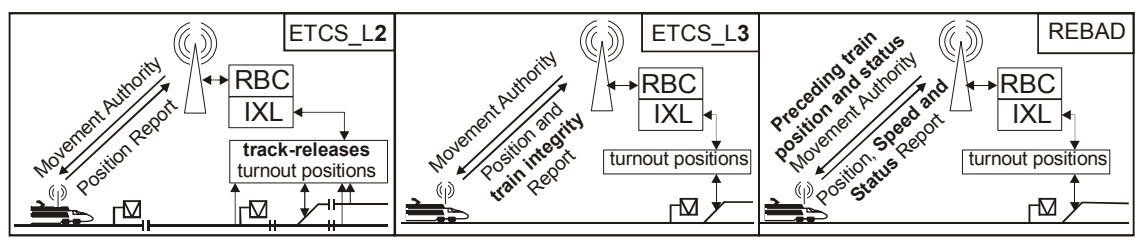

Figure 5: Main exchanges between ground and trains for ETCS_Level 2, ETCS_Level 3 and REBAD.

\subsection{Needs of new ETCS messages for REBAD}

The Train Position Report provided by ETCS_L2 and ETCS_L3 contains already data about position, speed and train integrity (Packet 0 or 1 - Message 136 - [9]). However, speed is not accurate (5 km/h steps).

For REBAD, some new parameters should be added to the train position report:

- $\quad$ the minimum distance to stop with full use of service brakes;

- $\quad$ the status of the train. This information could be given by either the Yes/No value coming out from the emergency onboard unit, or could transmit all the input data of this unit (cf. table 3).

The status of a preceding train must be regularly built up and transmitted to the following train. The interruption of the transmission to the following train leads to a service braking and, if the transmission is not restored, to an emergency stop. 
Table 3: $\quad$ Inputs and outputs of some onboard units.

\begin{tabular}{|c|c|c|c|}
\hline Units & ETCS_L2 & ETCS_L3 & REBAD \\
\hline $\begin{array}{l}\text { ODO } \\
\text { (ODOmetry) } \\
\text { Outputs: } \\
\text { Position, Speed } \\
\text { Acceleration }\end{array}$ & $\begin{array}{l}\text { Inputs: } \\
\text { Wheel sensors, } \\
\text { Radars, } \\
\text { Accelerometers, } \\
\text { Balises, etc. }\end{array}$ & $\begin{array}{l}\text { Input: } \\
\text { same as for L2 }\end{array}$ & $\begin{array}{l}\text { Input: } \\
\text { same as for } \\
\text { ETCS_L2 and L3 }\end{array}$ \\
\hline $\begin{array}{l}\text { TIN } \\
\text { (Train INtegrity) } \\
\text { Output: } \\
\text { Yes/No } \\
\end{array}$ & --- & $\begin{array}{l}\text { Inputs: } \\
\text { Braking pipes pressure } \\
\text { sensors, } \\
\text { Train loops, etc. }\end{array}$ & $\begin{array}{l}\text { Input: } \\
\text { if necessary: } \\
\text { same as for ETCS_L3 }\end{array}$ \\
\hline $\begin{array}{l}\text { EME } \\
\text { (EMErgency) } \\
\text { Output: } \\
\text { Yes/No }\end{array}$ & --- & --- & $\begin{array}{l}\text { Inputs: } \\
\text { Acceleration } \\
\text { TIN output, } \\
\text { Braking pipes pressure } \\
\text { sensors, } \\
\text { Derailment sensors, } \\
\text { Emergency brake } \\
\text { interventions }\end{array}$ \\
\hline
\end{tabular}

The movement authorities and the train status of the preceding train must be transmitted to the following train very often and in a safe way. One has to pay attention to the security and capacity of the GSM-R transmission. Perhaps the transmission of a train status to its following train could also bypass the RBC.

\section{Application case: siding on high speed line}

Considering two trains running with REBAD with a minimal headway and a siding on a high speed line, three cases are possible.

\subsection{Both trains stay on the same track}

In this case, the two trains block the turnout during a certain time. When the first train clears it, the turnout must continue to be locked by the second train.

\subsection{First train takes the diverting route}

In this case, the position of the turnout has to be changed after the first train clears the turnout. The second train will lose a minimum of time if its speed is regulated some time before. The advantage of REBAD versus ETCS is also visible in this case: as soon as train T1 clears the turnout the second train could be at full speed at location P1 (cf. fig. 6-a).

\subsection{Second train takes the diverting route}

In this case, the position of the turnout has also to be changed after the first train clears the turnout. The need of a specific speed regulation is depending not only on all parameters visible in figure 3 but on the speed difference between ceiling speed $v_{c}$ and diverting speed $v_{d}$ too. Greater is the difference, smaller is the 
probability to need a specific speed regulation. Figure 6-b shows a case in which $v_{\mathrm{x}}$ is between $\mathrm{v}_{\mathrm{c}}$ and $\mathrm{v}_{\mathrm{d}}$. For a low $\mathrm{v}_{\mathrm{d}}$, a short diverting speed, a brief $\mathrm{t}_{\mathrm{s}}$, and a large difference between EBmD2 and P2, train T2 must not overrun location P1b when T1 leaves the turnout. In other cases, it is the location P1a that has to be considered.

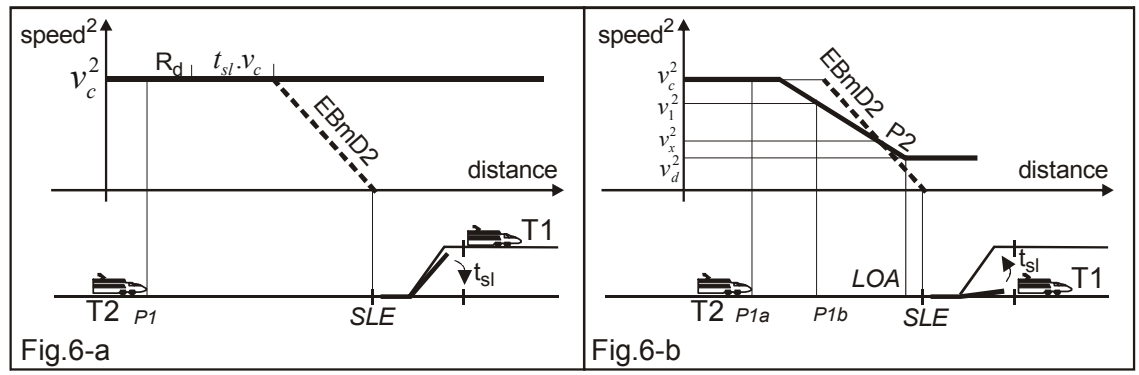

Figure 6: Change of position of a turnout under the protection of an emergency brake curve. With: $t_{\mathrm{sl}}$ : maximal time needed to switch and locked the turnout.

\section{Conclusion}

With the combination of service brake relative distances and emergency brake absolute distances, REBAD provides a performing mode of running. This new mode, using an ATO system, allows not only schedulers to introduce shorter buffer times during timetable construction, but offers also significant savings of time in case of operational disturbance, in particular for high speed lines.

This enhanced mode, however, should be turned off in some peculiar circumstances, such as very bad adhesion conditions.

\section{Acronyms}

$\begin{array}{llll}\text { ATP } & \text { Automatic Train Protection } & \\ \text { BACC } & \begin{array}{l}\text { Blocco Automatico di Corrente Codificato } \\ \text { CIR-ELKE }\end{array} & \begin{array}{l}\text { Computer Integrated Railroading } \\ \text { Leistungsfähigkeit im Kernnetz }\end{array} & \text { Erhöhung der } \\ \text { EOA } & \begin{array}{l}\text { End Of Authority } \\ \text { EbmD }\end{array} & \text { Emergency Brake minimal Deceleration } \\ \text { EBMd } & \text { Emergency Brake Maximal distance } & \\ \text { ERTMS } & \text { European Railway Train Management System } \\ \text { EP } & \text { Electro-Pneumatic } \\ \text { ETCS } & \text { European Train Control System } \\ \text { ETML } & \text { European Train Management Layer } \\ \text { GSM-R } & \text { Global System for Mobile communications - Railways } \\ \text { GUI } & \text { Guidance Curve } \\ \text { HSL } & \text { High Speed Lines }\end{array}$




$\begin{array}{ll}\text { I } & \text { Indication Curve or Indication point } \\ \text { INDUSI } & \text { INDUktive ZugSIcherung } \\ \text { IXL } & \text { Interlocking } \\ \text { KVB } & \text { Contrôle de Vitesse par Balises } \\ \text { LOA } & \text { Limit Of Authority } \\ \text { LZB } & \text { LinienZugBeeinflussung } \\ \text { P } & \text { Permitted Deceleration } \\ \text { PZB } & \text { Punktförmige ZugBeeinflussung } \\ \text { RBC } & \text { Radio Block Centre } \\ \text { REBAD } & \text { Running with Emergency Brake Absolute Distance } \\ \text { SBmD } & \text { System Brake minimal Deceleration } \\ \text { SBMD } & \text { System Brake Maximal Deceleration } \\ \text { SBmd } & \text { System Brake minimal distance } \\ \text { SBMd } & \text { System Brake Maximal distance } \\ \text { SL } & \text { Supervised Location } \\ \text { SLE } & \text { Supervised Location in case of Emergency } \\ \text { TSI } & \text { Technical Specification for Interoperability } \\ \text { TVM } & \text { Transmission Voie-Machine }\end{array}$

\section{References}

[1] Association of European Railway Industries UNIFE, ERTMS/ETCS - A Powerful Tool to make Rail Traffic more Efficient, Signal+Draht (98) $12 / 2006$

[2] Maschek U., Baumgartner S., Theeg G., Comparison of international high speed signalling and control, Signal+Draht (98) 5/2006

[3] Geiss G., CIR-ELKE in Betrieb, Eisenbahningenieur (53) 9/2002

[4] Wendler E., Influence of ETCS on line capacity - UIC ERTMS Conference, Berne 11-13 September 2007

[5] TSI-HS-RS: Technical Specification for Interoperability - High-Speed Rolling Stock - European Commission decision 2002/735/EC

[6] Braun A., Aufstellen von Bremstafeln für Strecken mit Linienzugbeeinflussung, ZEV-Glas. Ann 112 (1998) Nr. 4

[7] Gröpler O., Braking curves and models for ETCS, DB_AG, Minden, 2006

[8] Castan P.: Evolution of Signalling Systems and Implementation of ETCS on New High Speed Lines, Signal+Draht (98) 12/2006

[9] ERTMS/ETCS - Class 1 - SRS Chapter 8 SUBSET-026-7 and SUBSET-026-8 v230 - Packet number 58: Position report and Message number 136: Train Position Report 